\title{
Supplement to \\ Dynamical drivers of Greenland blocking in climate models
}

Table S1: Resolution and number of member for the HAPPI models. Further information can be found in Mitchell et al. (2017) and Li et al. (2018).

\begin{tabular}{ccccc}
\hline Model & Horizontal grid & lat $\times$ lon & Vertical levels & Members \\
\hline CAM4-2degree & $1.9^{\circ} \times 2.5^{\circ}$ & $64 \times 128$ & 26 & 501 \\
CanAM4 & T63 & $96 \times 192$ & 35 & 100 \\
ECHAM6.3-LR & T63 & $96 \times 192$ & 47 & 100 \\
MIROC5 & T85 & $128 \times 256$ & 40 & 100 \\
NorESM1-HAPPI & $0.94^{\circ} \times 1.25^{\circ}$ & $192 \times 288$ & 26 & 125 \\
\hline
\end{tabular}


Blocking frequency - DJF - 2006-2015 (All-Hist)

(a) NorESM native grid

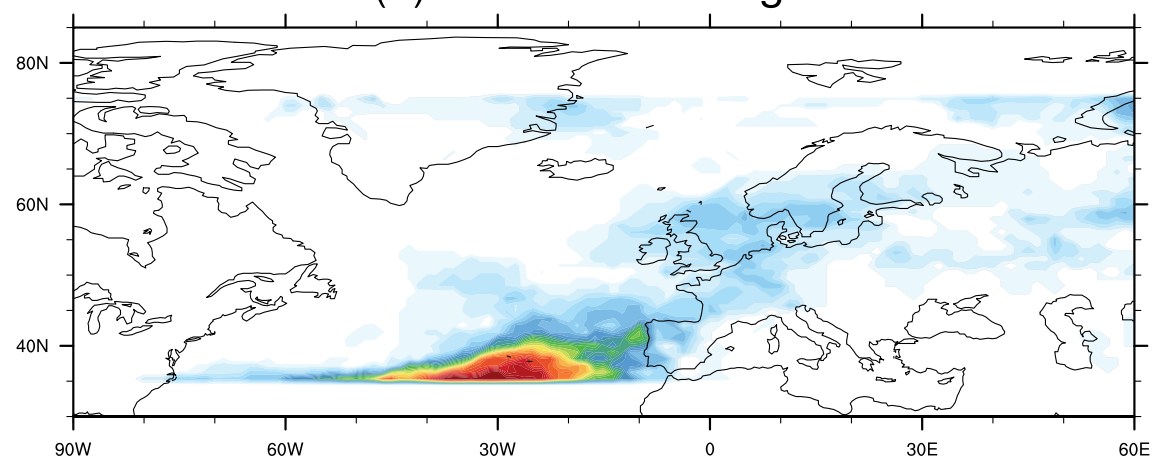

(b) NorESM regridded 2x2deg

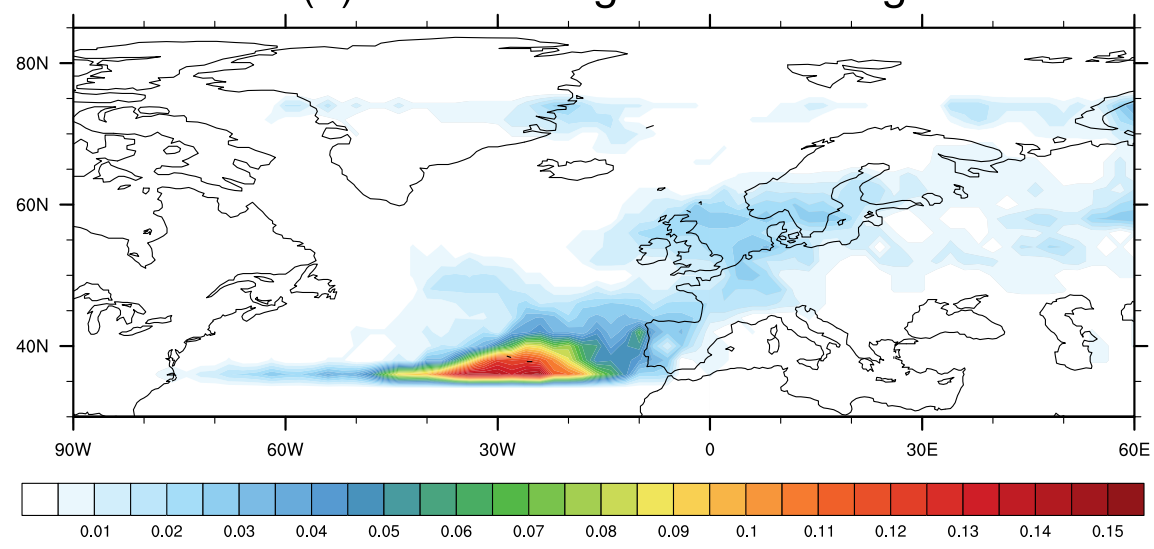

Figure S1: Difference of blocking frequency where blocking is detected using (a) the geopotential field on the model grid and (b) the geopotential interpolated on a $2^{\circ} \times 2^{\circ}$ grid geopotential fields. 


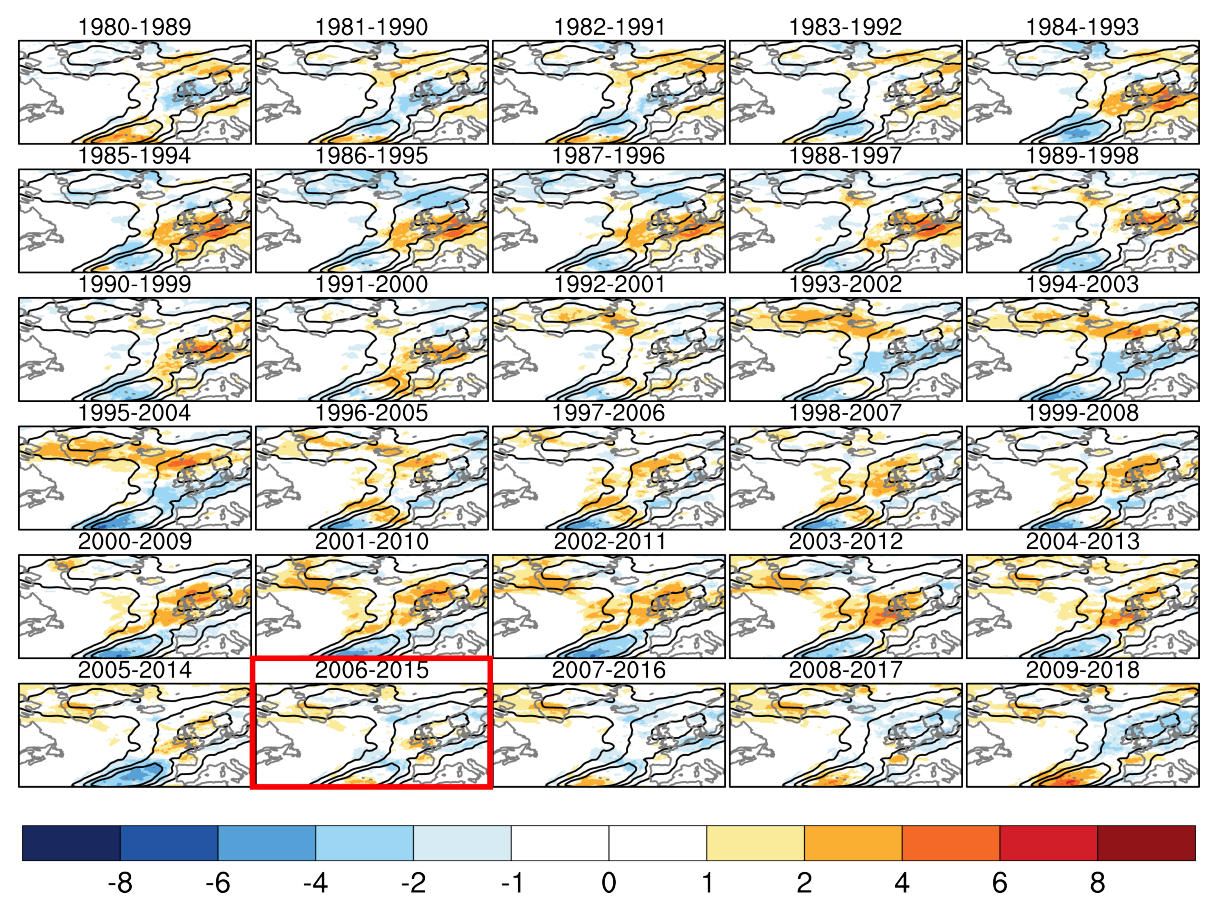

Figure S2: ERA-Interim blocking climatology differences for different decades. Black lines show the 2, 4 and 6\% contours for the 40 years (1979-2018) DJF ERA-Interim climatology. Shadings show for each 9-DJF (years given above each panel) the anomalies from the 40 years climatology (in \%). The red frame shows the 2006-2015 (i.e. December 2006 to February 2015) period used in this study. None of the 9-year climatologies are in any regions statistically different (t-test at 0.1 level) from the 40-year mean. 
(a) CAM4-2degree

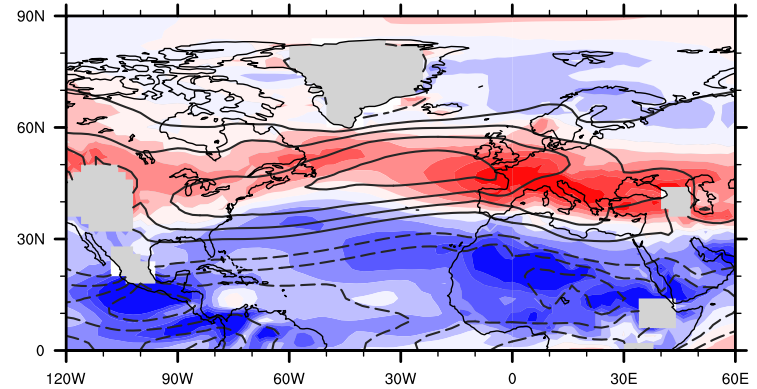

(c) ECHAM6.3-LR

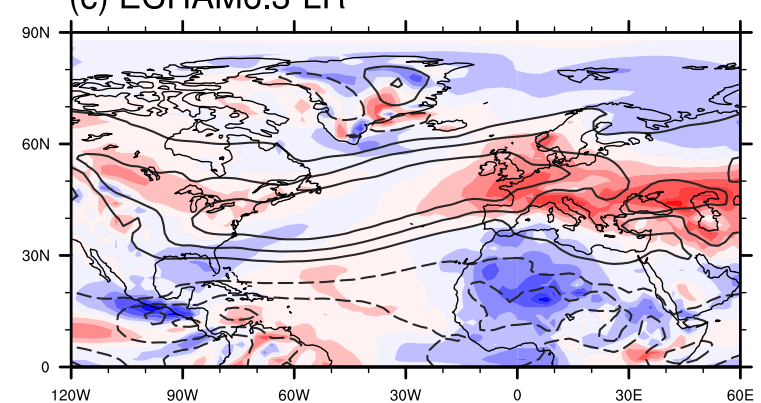

(e) NorESM1-Happi

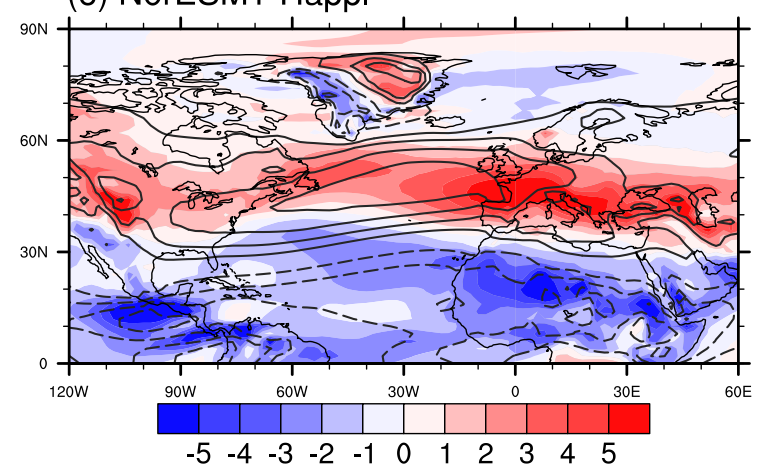

(b) CanAM4

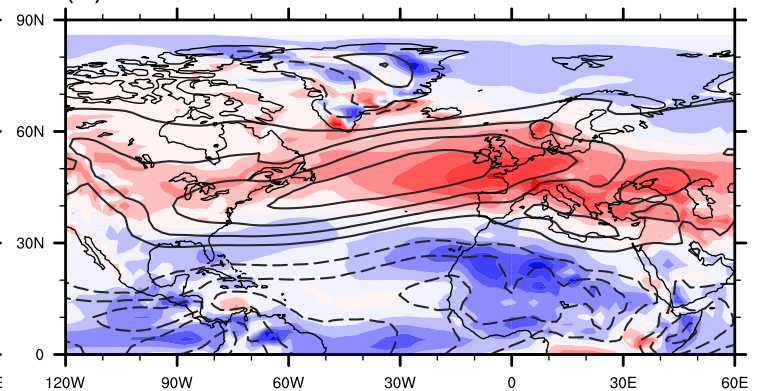

(d) MIROC5
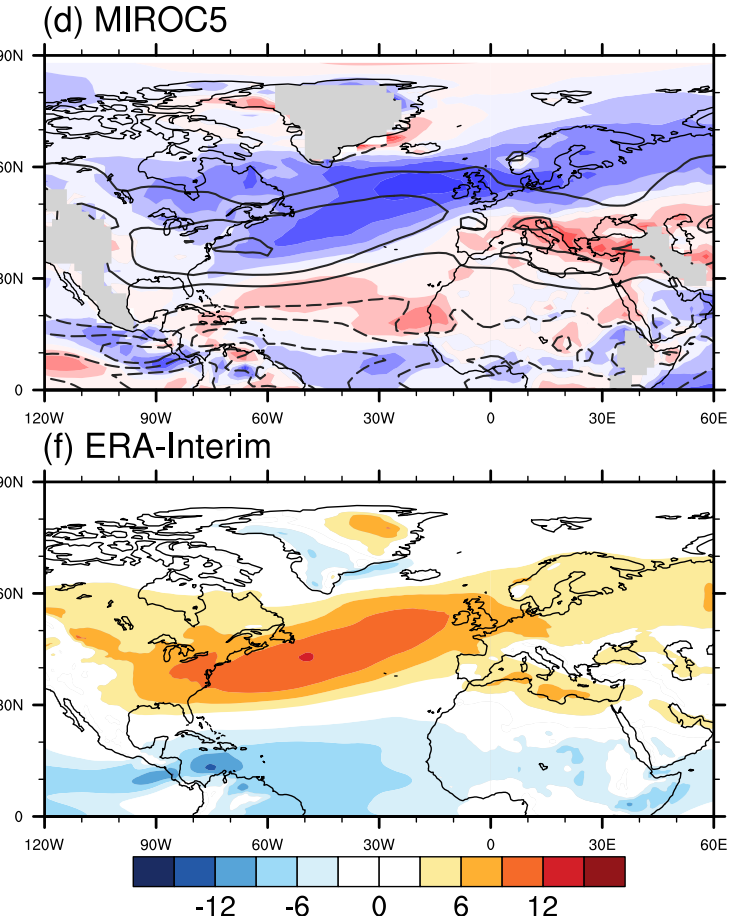

Figure S3: Bias in winter zonal wind at $850 \mathrm{hPa}$ (shading), overlapped by the model climatology (contours, interval: $3 \mathrm{~m} \mathrm{~s}^{-1}$, zero-contour omitted). Bias are computed with respect to ERA-Interim (2006-2015) shown in panel (f). 
(a) CAM4-2degree

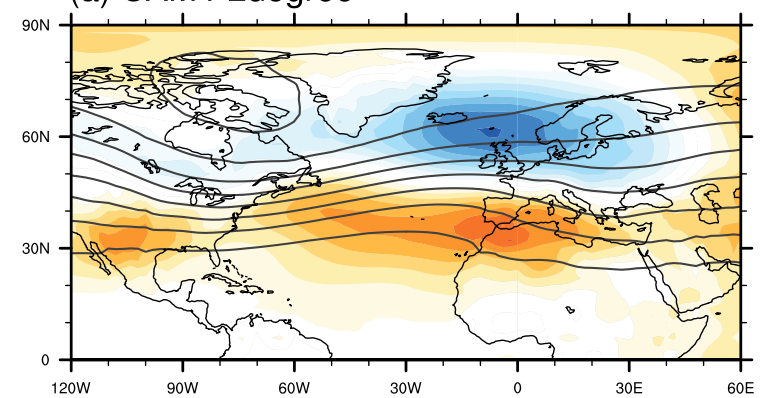

(c) ECHAM6.3-LR

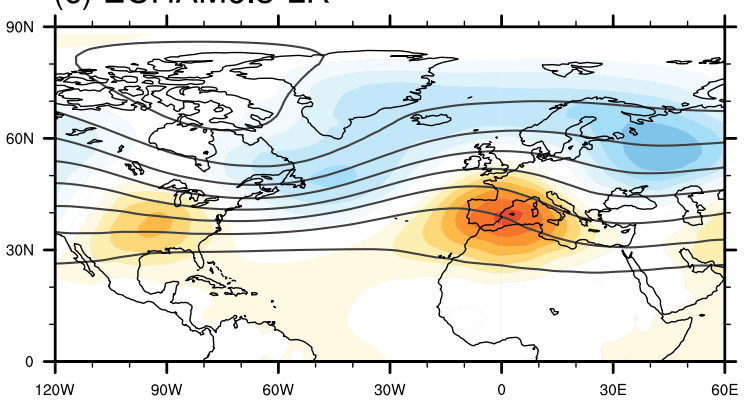

(e) NorESM1-HAPPI

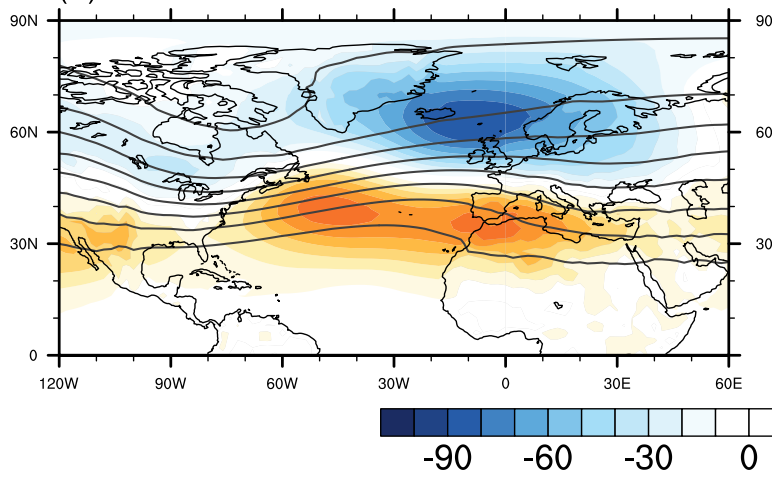

(b) CanAM4

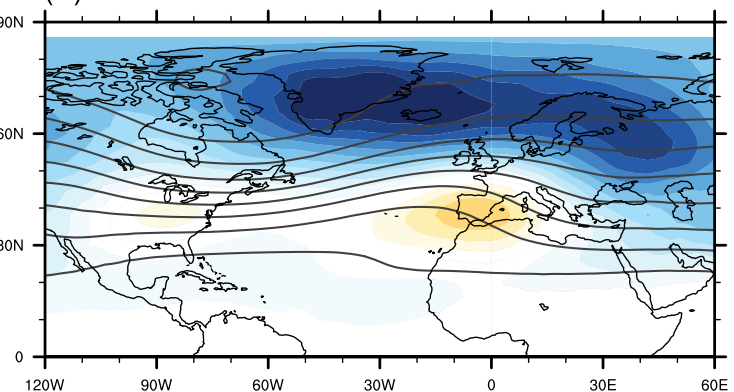

(d) MIROC5

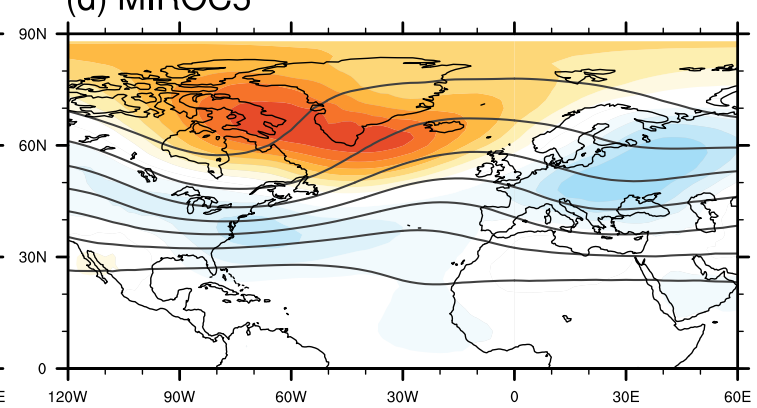

(f) ERA-Interim

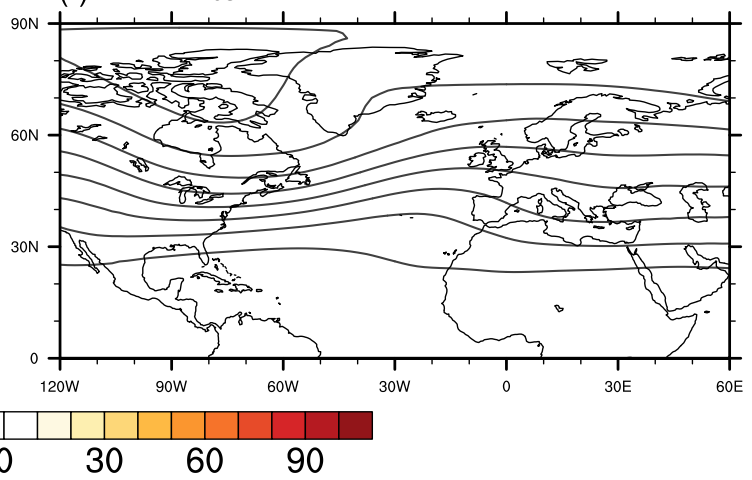

Figure S4: Bias of the ensemble mean 500-hPa geopotential height (shading, unit: $\mathrm{m}$ ) and ensemble mean of the 500-hPa geopotential height (contours, interval: $100 \mathrm{~m}$ ). Bias are computed with respect to ERA-Interim (2006-2015) shown in panel (f). 
(a) CAM4-2degree

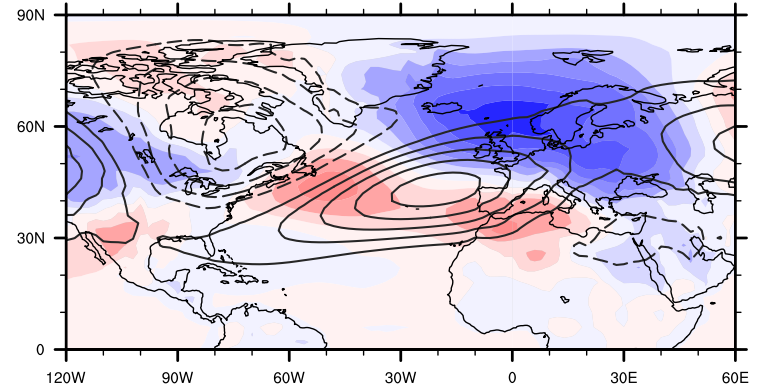

(c) ECHAM6.3-LR

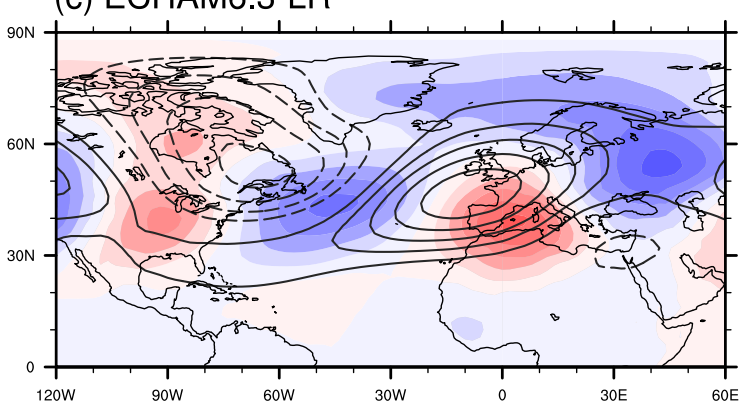

(e) NorESM1-Happi

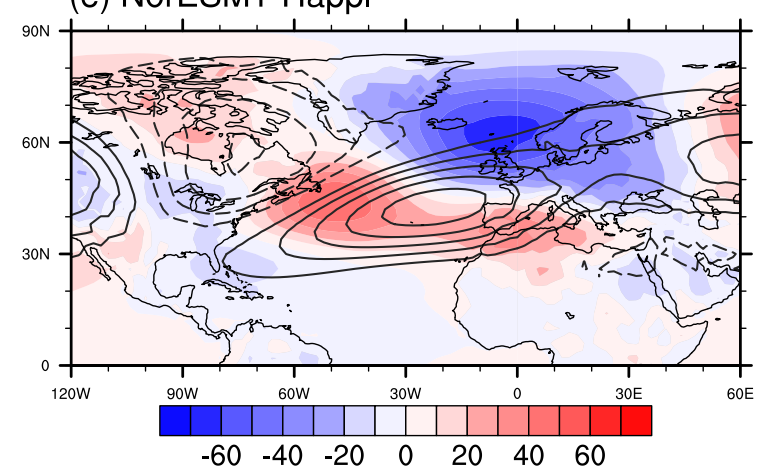

(b) CanAM4

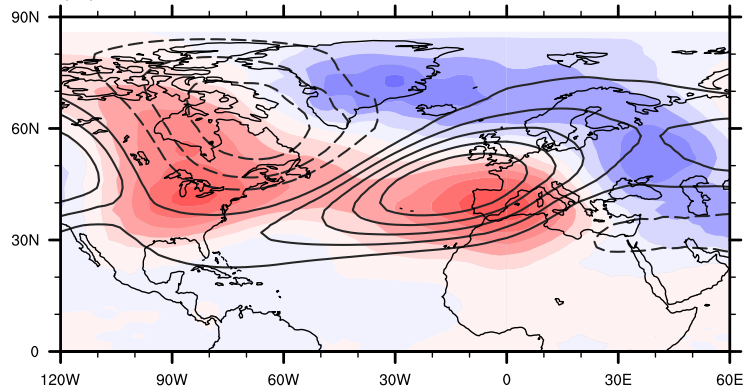

(d) MIROC5
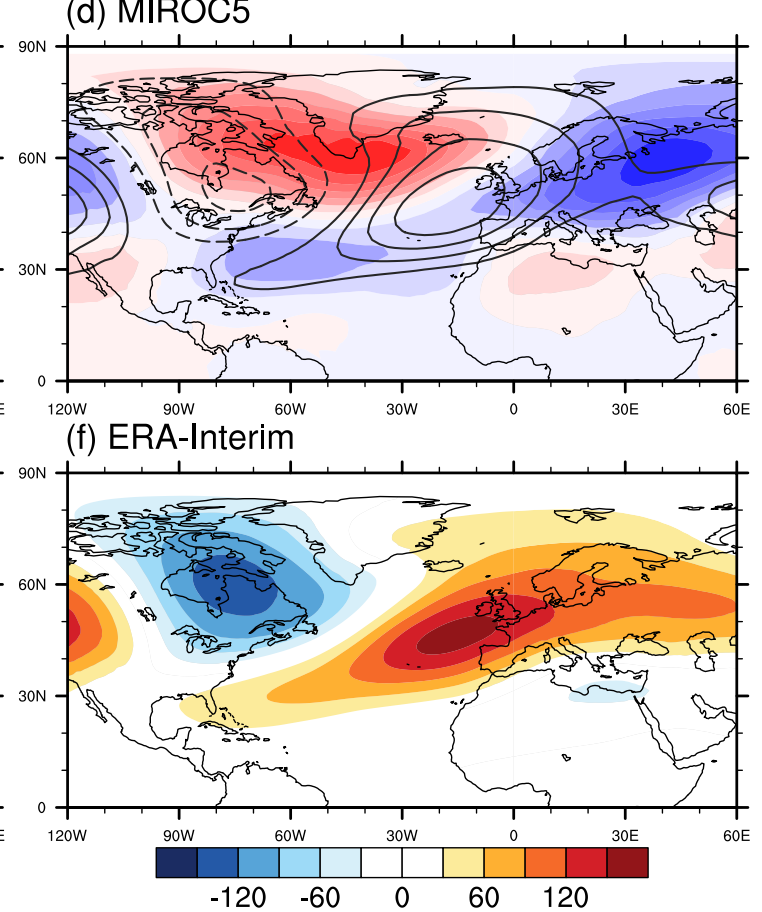

Figure S5: (a-e) Bias in winter stationary waves at $500 \mathrm{hPa}$ (shading), overlapped by the model climatology (contours, interval: $30 \mathrm{~m}$, zero-contour omitted). Bias are computed with respect to ERA-Interim (2006-2015) shown in panel (f). 

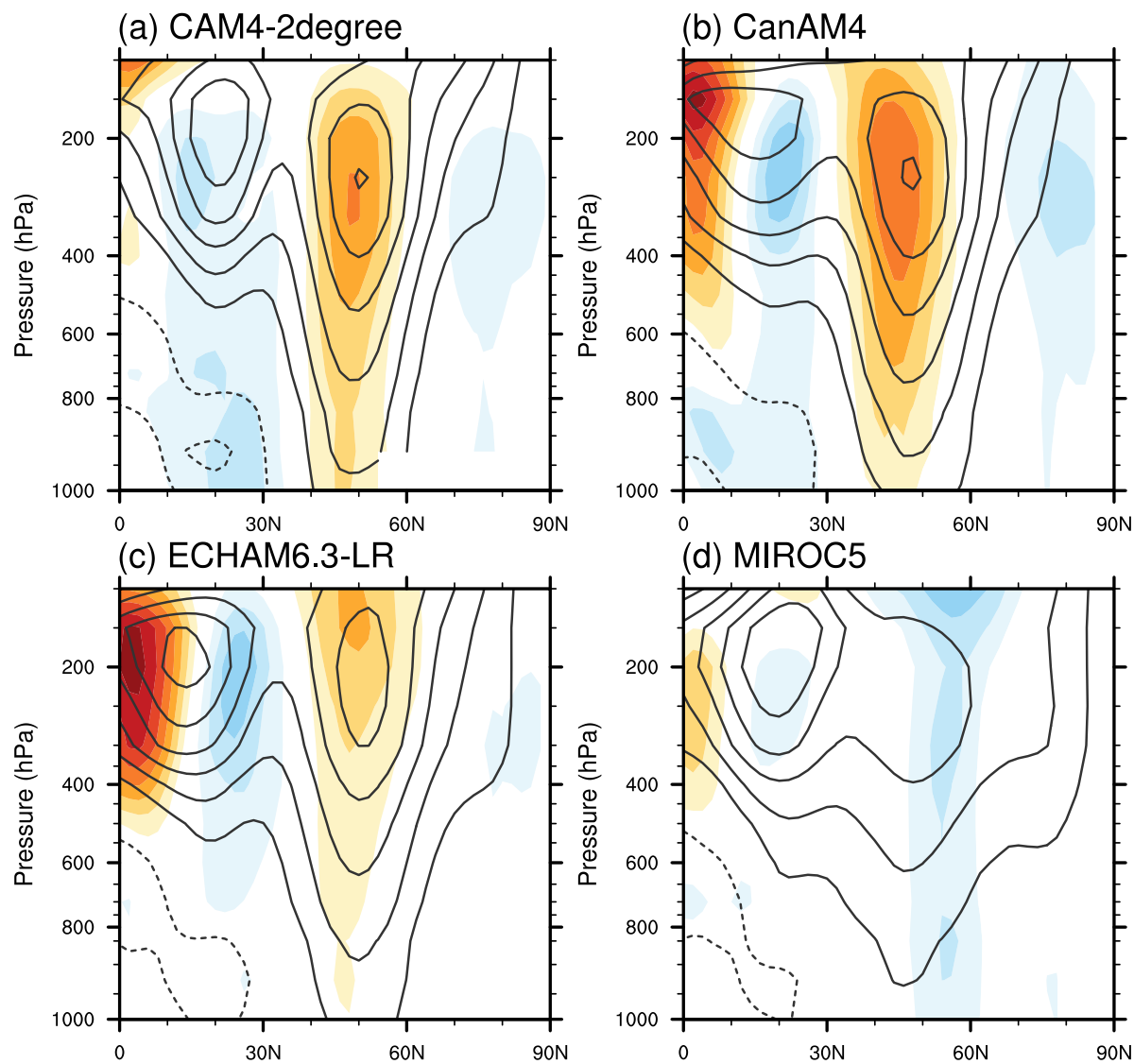

(d) MIROC5
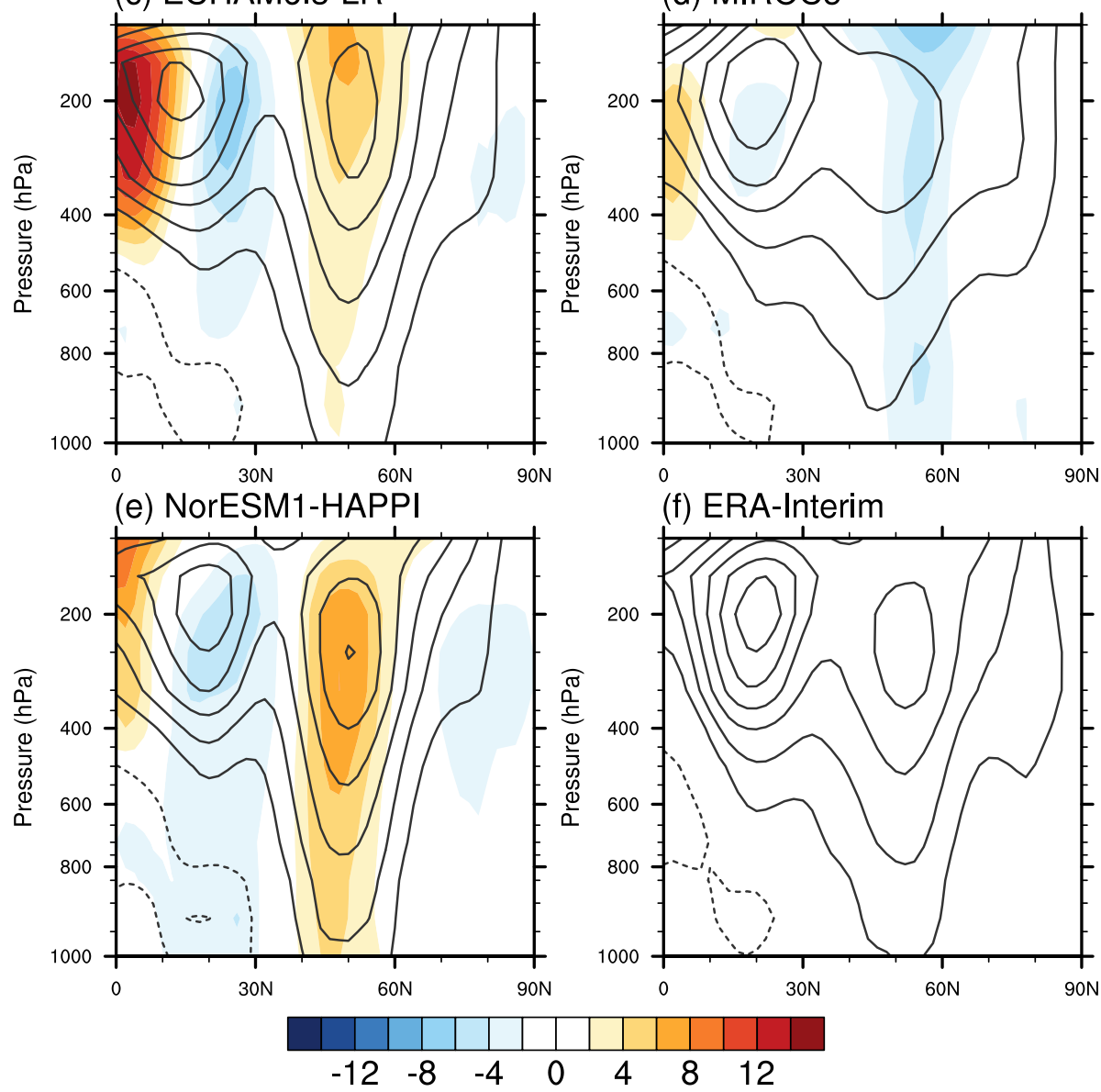

Figure S6: Cross-sections of the bias of the DJF ensemble mean of the zonal mean zonal wind (shading, unit: $\mathrm{m} \mathrm{s}^{-1}$ ) overlapped by the ensemble mean zonal mean zonal wind (contours, interval: $5 \mathrm{~ms}^{-1}$, zero-contour omitted) for (a-e) the five HAPPI models. The bias is computed with respect to ERAInterim (2006-2015) shown in panel (f). The zonal mean is taken between $30^{\circ} \mathrm{W}-0^{\circ}$. 
(a) CAM4-2degree

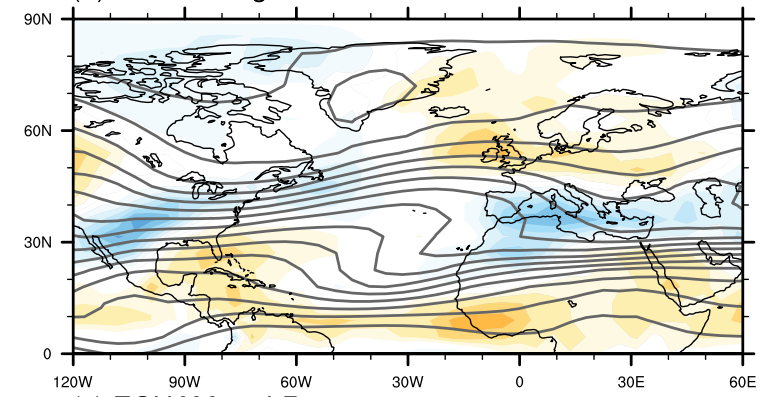

(c) ECHAM6.3-LR

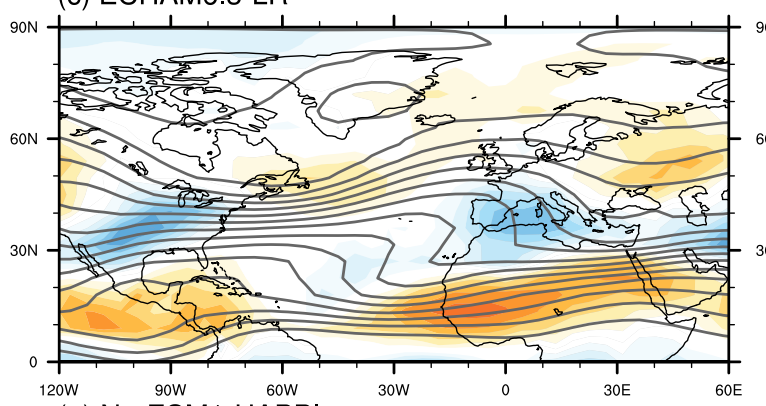

(e) NorESM1-HAPPI (b) CanAM4

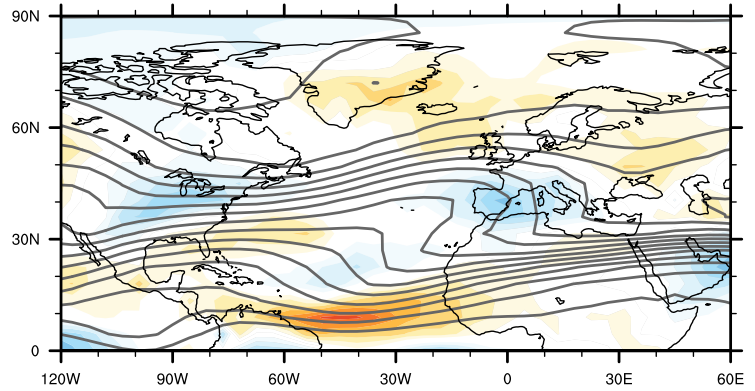

(d) MIROC5
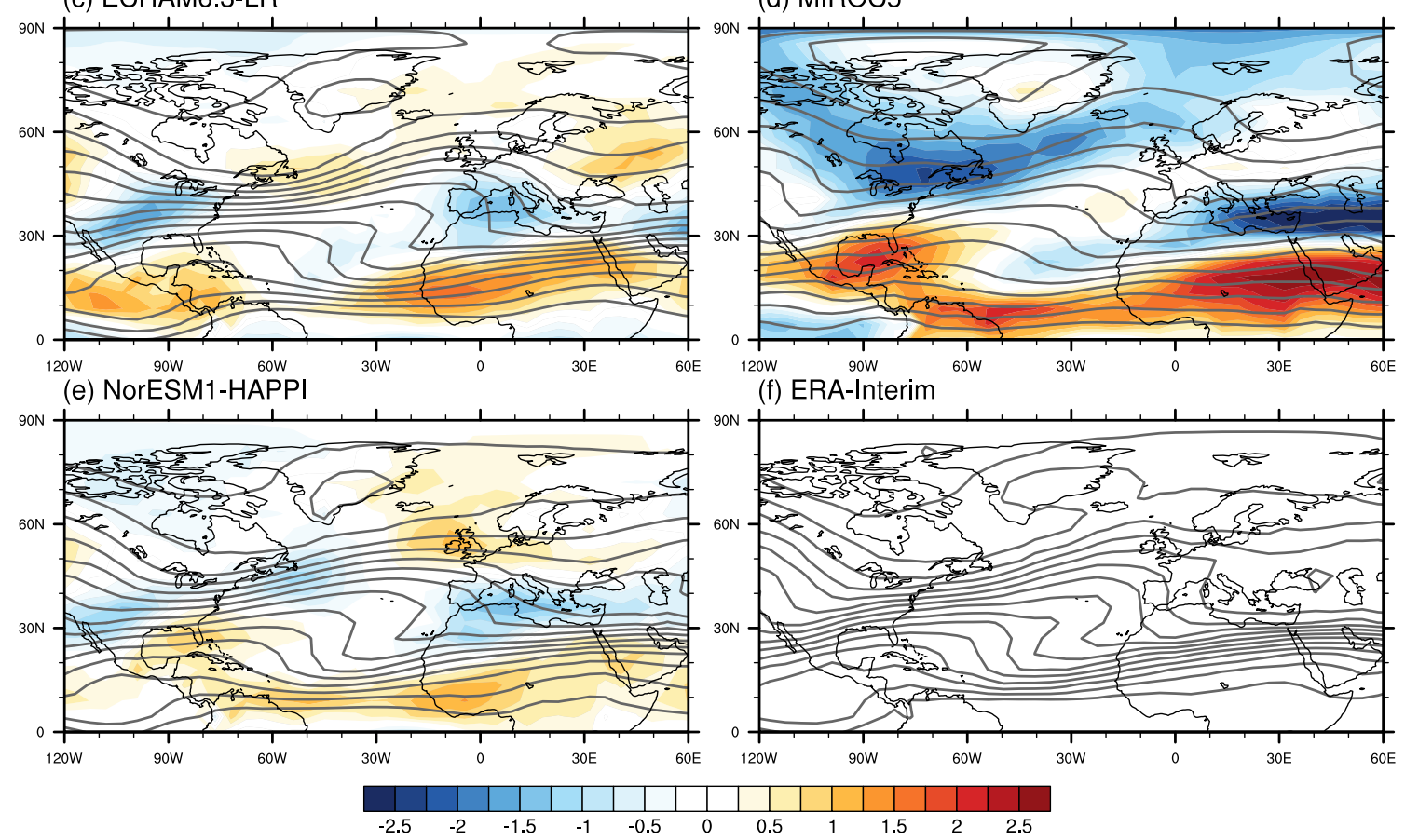

(f) ERA-Interim
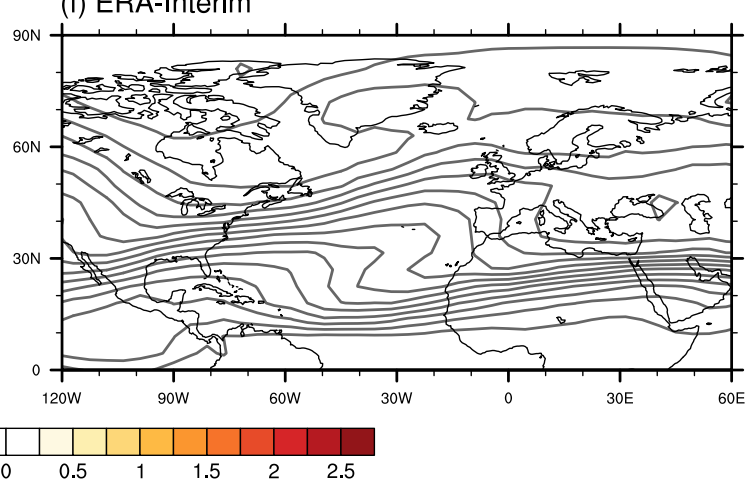

Figure S7: Bias of the ensemble mean 250-hPa absolute vorticity (shading, unit: $10^{-5} \mathrm{~s}^{-1}$ ) and ensemble mean 250-hPa absolute vorticity (contours, interval: $10^{-5} \mathrm{~s}^{-1}$ ). Bias are computed with respect to ERA-Interim (2006-2015) shown in panel (f). 

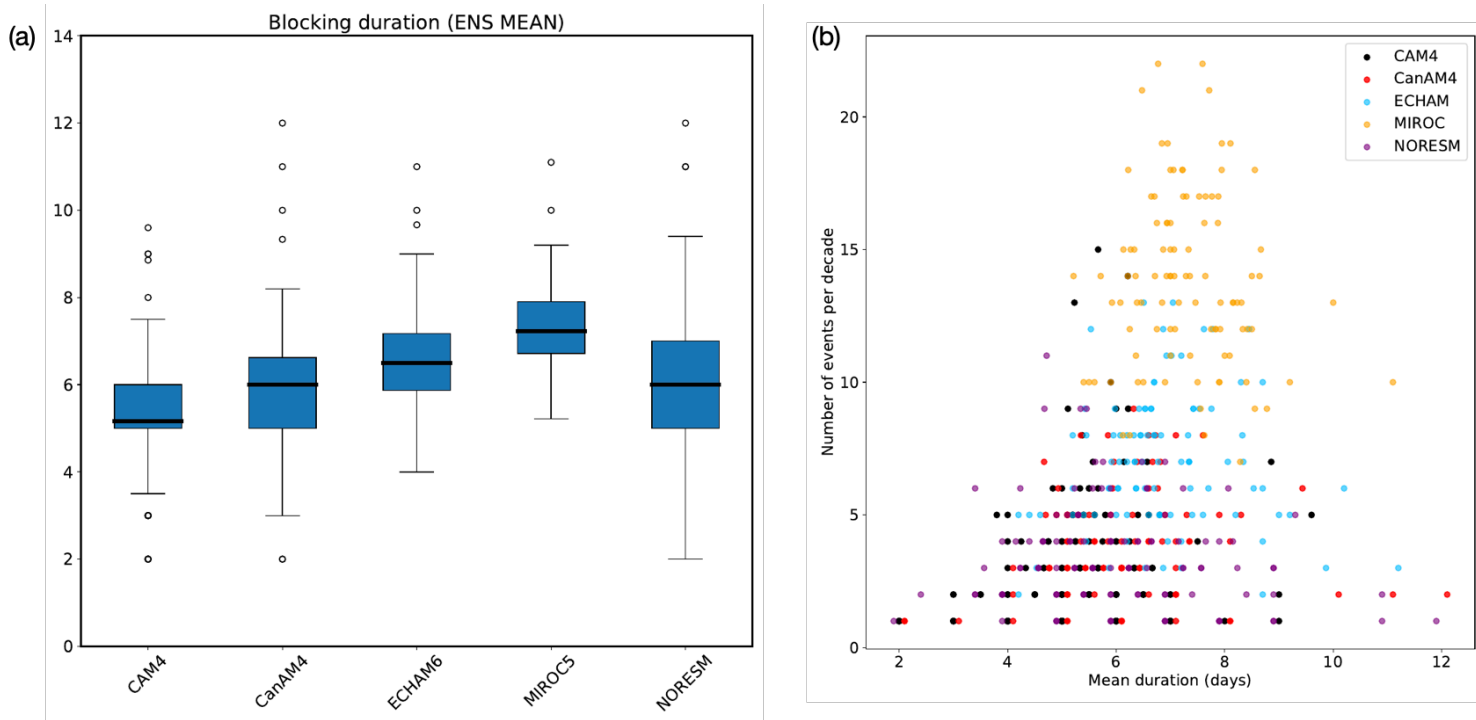

Figure S8: (Left) Ensemble distribution of the mean blocking duration for each member. The boxes show the interquartile range (IQR) and the dots represent values lower (greater) than 1.5 IQR represented by the whiskers. (Right) Number of Greenland blocking events as a function of their mean duration for each member (dots) of each model (colors). 
(a) CAM4-2degree

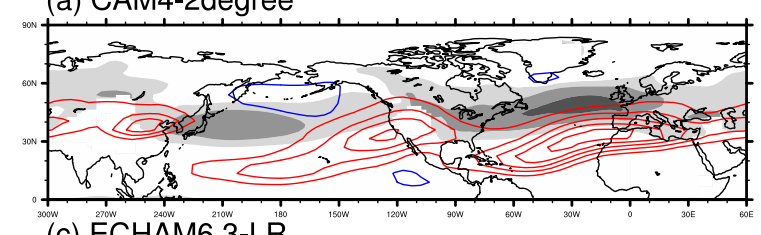

(b) CanAM4

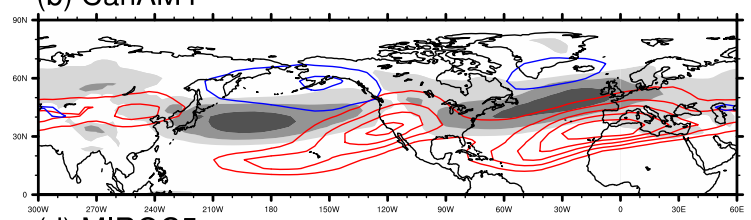

(d) MIROC5

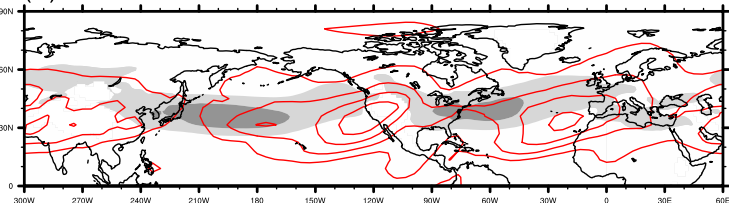

(f) ERA-Interim

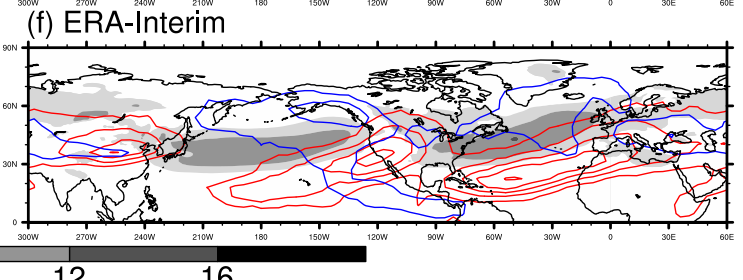

Figure S9: Ensemble mean of DJF Rossby wave breaking frequency for (a-e) the five HAPPI models and (f) ERA-Interim (blue (red) contours for CWB (AWB), first contour: 0.1 day $^{-1}$ and interval: 0.05 day $^{-1}$ ) surperimposed to the ensemble mean zonal wind at $850 \mathrm{hPa}$ (shading, in $\mathrm{m} \mathrm{s}^{-1}$ ). 
(a) CAM4-2degree

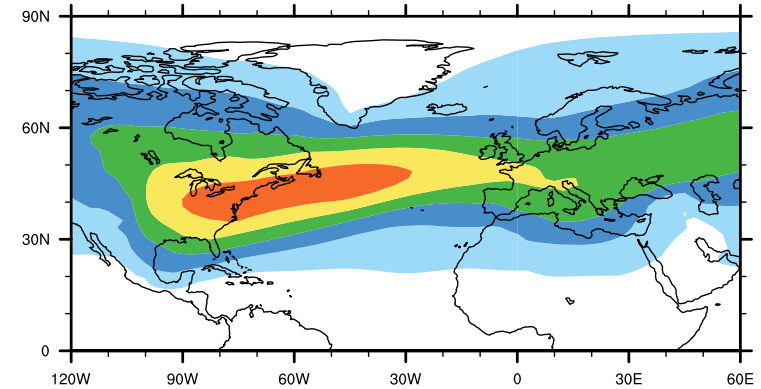

(c) ECHAM6.3-LR

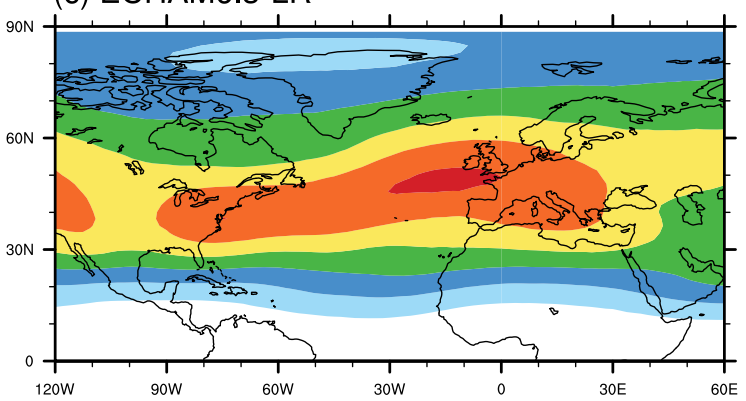

(e) NorESM1-HAPPI

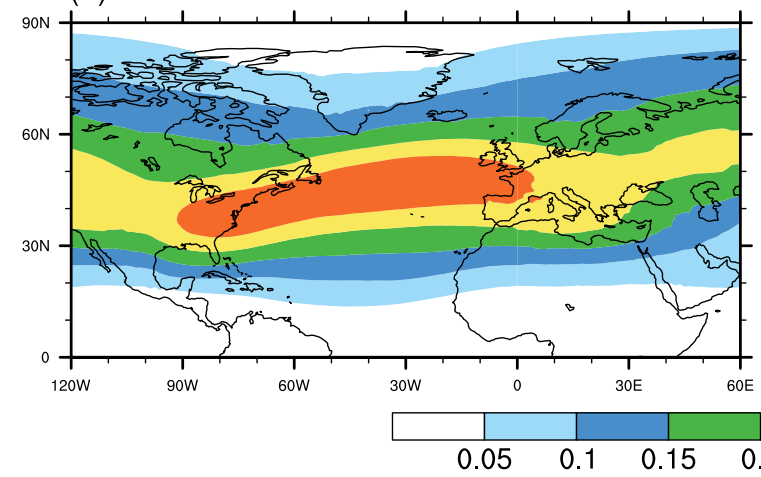

(b) CanAM4

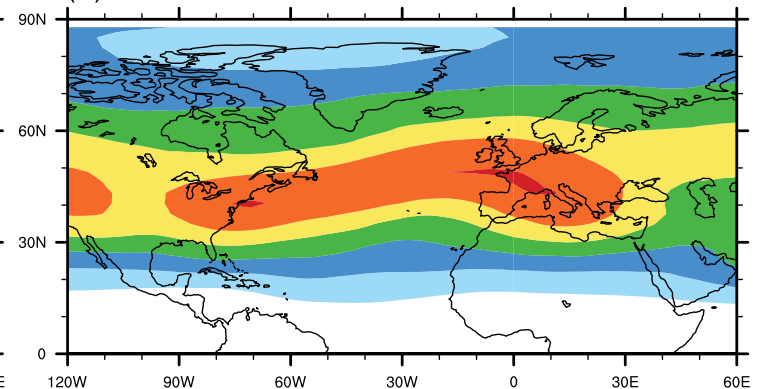

(d) MIROC5

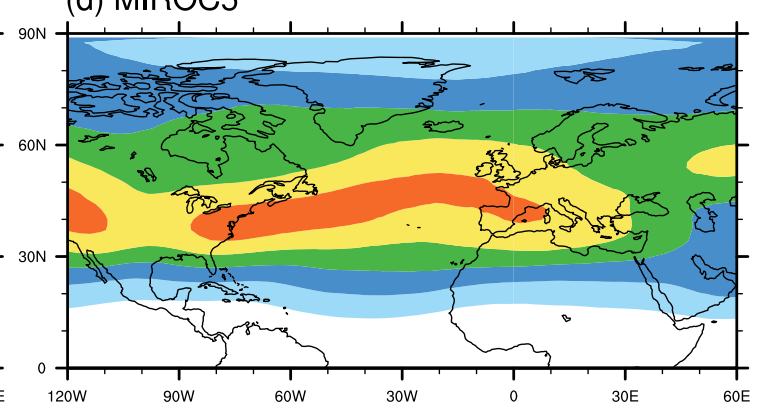

(f) ERA-Interim

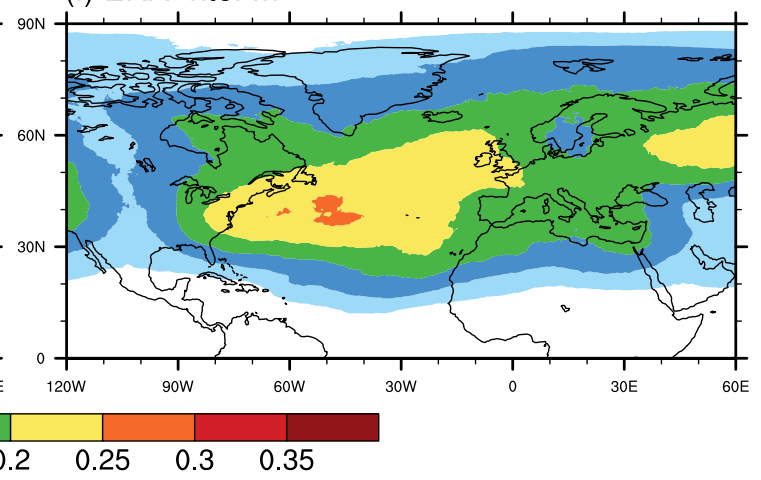

Figure S10: DJF mean anticyclone frequencies for (a-e) the five HAPPI models and (f) ERA-Interim. Unit: fraction of the time. 
(a) CAM4-2degree

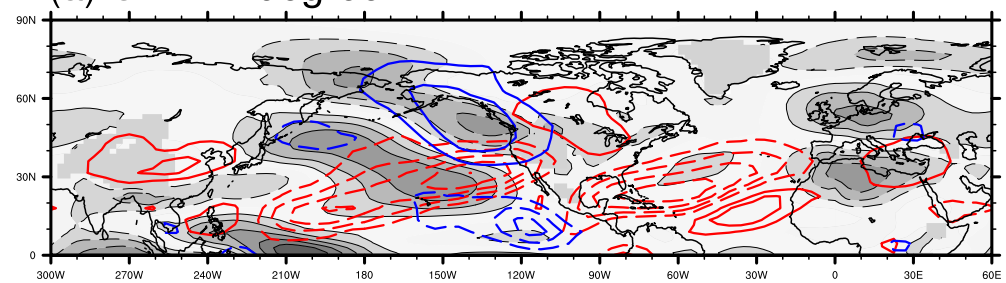

(b) CanAM4

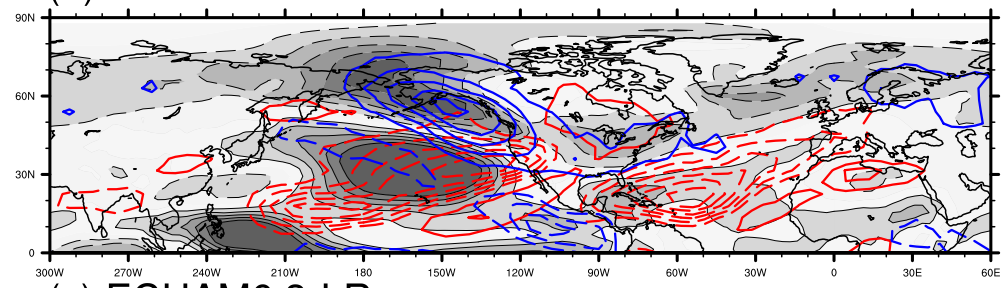

(c) ECHAM6.3-LR

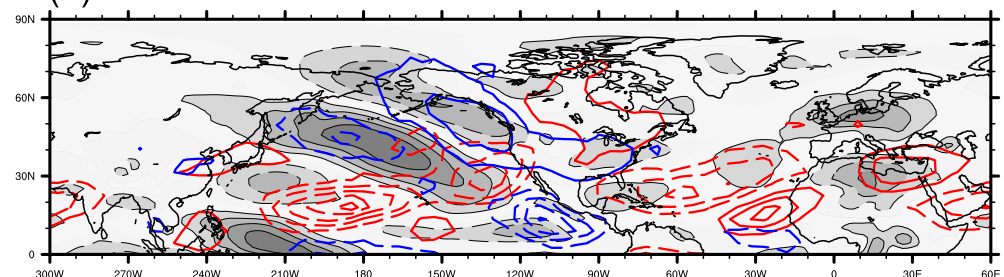

(d) MIROCC5

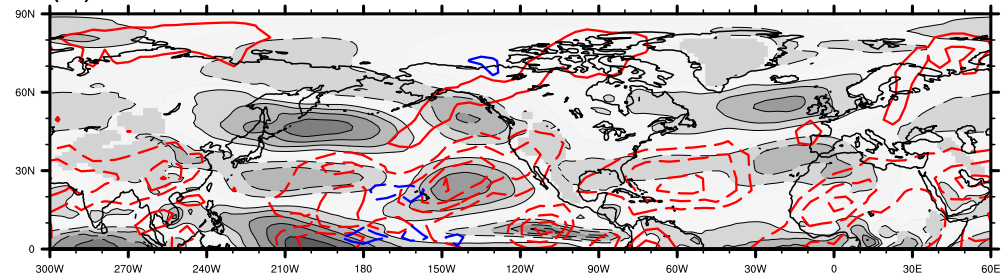

(e) NorESM1-HAPPI

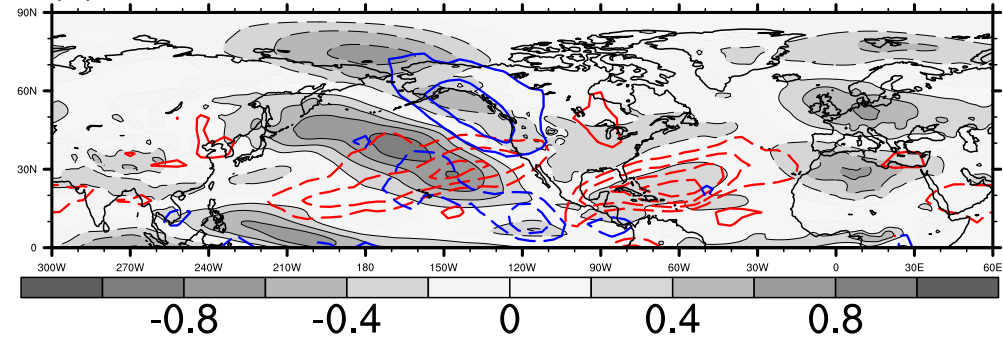

Figure S11: Ensemble mean response of Rossby wave breaking frequency (blue contours for CWB and red contours for AWB, solid lines for positive values and dashed lines for negative values, zero-contour omitted, interval: 0.005 day $^{-1}$ ) and $850-\mathrm{hPa}$ zonal wind (black contours and gray shading, unit: $\mathrm{m}$ $\mathrm{s}^{-1}$ ) for DJF for the five HAPPI models. 